\title{
B-cell-activating factor is a regulator of adipokines and a possible mediator between adipocytes and macrophages
}

\author{
Mi-Young Kim, Do-Hwan Kim and Myoung-Sool Do
}

3T3-L1 adipocytes express the B-cell-activating factor (BAFF) and three different BAFF receptors (BAFF-Rs). Furthermore, BAFF expression is regulated by inflammatory modulators, such as tumor necrosis factor- $\alpha$ and rosiglitazone. Here we investigated the function of BAFF in 3T3-L1 adipocytes and RAW 264.7 macrophages. We examined adipokine expression in 3T3-L1 adipocytes treated with $10 \mathrm{ng} \mathrm{ml}^{-1}$ BAFF. We also examined inflammatory molecule expression in RAW 264.7 macrophages treated with 10 or $100 \mathrm{ng} \mathrm{ml}^{-1}$ BAFF. We examined BAFF expression in the coculture of 3T3-L1 adipocytes and RAW 264.7 macrophages, as well as in white adipose tissue (WAT) of diet-induced obese (DIO) mice. We found that BAFF decreases leptin and adiponectin expression, but increases the expression of proinflammatory adipokines monocyte chemotactic protein-1, interleukin-6 (IL-6), cyclooxygenase-2 (COX-2) and haptoglobin. Coculturing the two cell types resulted in increased BAFF mRNA and protein expression, as well as modulation of BAFF-R mRNA expression in both cell types. These data indicate that BAFF might mediate adipocyte and macrophage interaction. When RAW 264.7 macrophages were treated with BAFF, BAFF-R expression was modulated as in coculture, and nitric oxide synthase and IL- 6 expression increased. BAFF expression also increased in WAT of DIO mice. We propose that BAFF can regulate adipokine expression and possibly mediate adipocyte and macrophage interaction.

Experimental \& Molecular Medicine (2013) 45, e4; doi:10.1038/emm.2013.4; published online 10 January 2013

Keywords: 3T3-L1 adipocytes; B-cell-activating factor; coculture; diet-induced obesity; inflammation

\section{INTRODUCTION}

Adipose tissue expresses various cytokines, which are produced by adipocytes and called are adipokines. ${ }^{1}$ These adipokines have increasingly been shown to have important roles as mediators for linking adipose tissue and inflammation. The dysregulation of adipokine secretion is often observed in patients with obesity and is associated with increased development of many metabolic diseases such as type 2 diabetes, atherosclerosis and autoimmunity. ${ }^{2-6}$

B-cell-activation factor (BAFF) is a member of the tumor necrosis factor (TNF) superfamily of ligands. BAFF is also known as B-lymphocyte stimulator (BLyS); TNF- and ApoL-related leukocyte-expressed ligand-1 (TALL-1); TNF homolog that activates apoptosis, nuclear factor- $\mathrm{\kappa B}$ and $\mathrm{c}-\mathrm{Jun} \mathrm{NH}_{2}$ terminal kinase (THANK); TNF-superfamily member 13B (TNFSF13B); and zTNF4. $^{7-9}$ BAFF is a type II transmembrane protein, containing 285 amino acids. ${ }^{8}$ The soluble form of BAFF is cleaved by a furinlike protease, and its molecular weight is $17,038 \mathrm{Da}^{8,10}$
BAFF is primarily produced by myeloid lineage cells, activated $\mathrm{T}$ cells and dendritic cells. ${ }^{11,12}$ Its receptors are BAFF receptor (BAFF-R), TNF receptor homolog transmembrane activator and $\mathrm{Ca}^{2+}$ modulator and calcium modulating cyclophilin ligand (CAML) interactor (TACI), as well as B-cell maturation antigen (BCMA), ${ }^{9,13,14}$ which are usually expressed on $B$ cells and on a certain subset of $T$ cells; ${ }^{11-12,15}$ therefore, BAFF mainly affects B-cell proliferation and maturation. ${ }^{8}$

There are many kinds of adipokines, such as leptin and adiponectin, and proinflammatory adipokines, such as monocyte chemotactic protein-1 (MCP-1), interleukin-6 (IL-6), cyclooxygenase-2 (COX-2) and haptoglobin. Leptin is a well-known adipokine that regulates appetite and energy expenditure, and it is closely associated with obesity. ${ }^{16,17}$ Adiponectin is a modulator of insulin sensitivity and inflammation. During adipocyte differentiation, the expression of leptin increases, but that of adiponectin decreases. $.^{18} \mathrm{MCP}-1$ is 
a chemotactic factor that attracts macrophages to adipose tissue. ${ }^{19}$ IL-6 is a multifunctional cytokine, which promotes inflammation in damaged organ tissue by giving rise to secretion of other inflammatory cytokines. ${ }^{20,21}$ COX-2 is an enzyme that synthesizes prostaglandin $\mathrm{E}$ and therefore causes fever and inflammation. ${ }^{22}$ Haptoglobin is an inflammationinducible plasma protein. ${ }^{23}$

In an earlier study, we reported for the first time that BAFF is expressed in human Simpson-Golabi-Behmel syndrome adipocytes, and that BAFF expression increases after TNF- $\alpha$ treatment using a DNA microarray. ${ }^{24}$ It has also been reported that adipose tissue around breast cancer expresses $\mathrm{BAFF}^{25}$ and that BAFF and its receptors are expressed in adipocytes. ${ }^{26}$ BAFF has recently been shown to induce insulin resistance in vivo. ${ }^{27}$ Therefore, we proposed that BAFF might be a novel adipokine that links obesity and inflammation. ${ }^{28}$

In this study, we first investigated whether BAFF can function as a regulator of adipokine expression. Second, we investigated the ability of BAFF to act as a mediator for adipocyte and macrophage interaction by coculturing 3T3-L1 adipocytes and RAW 264.7 macrophages. Third, we showed that BAFF could modulate the expression of some inflammatory molecules in RAW 264.7 macrophages. Finally, we investigated the regulation of BAFF expression in white adipose tissues (WATs) of diet-induced obese (DIO) mice compared with those of control mice. Taken together, our results show that BAFF could be a regulator of adipokine expression and a mediator for adipocyte and macrophage interaction.

\section{MATERIALS AND METHODS}

\section{T3-L1 adipocyte culture}

3T3-L1 mouse pre-adipocytes purchased from ATCC (American Type Culture Collection, Manassas, VA, USA) were cultured in Dulbecco's modified Eagle's medium (Hyclone, Logan, UT, USA) medium containing $10 \%$ bovine calf serum (Hyclone) at $37^{\circ} \mathrm{C}$ in a humidified atmosphere of $5 \% \mathrm{CO}_{2}$. After 2 or 3 days, cells were subcultured into 35 -mm plates at a concentration of $3 \times 10^{4}$ cells per plate. At 2 days post confluence (designated 'day 0 '), cell differentiation was induced with a mixture of 3-isobutyl-1-methylxanthine (50 mm; SigmaAldrich, St Louis, MO, USA), dexamethasone (1 mm; Sigma-Aldrich) and insulin $\left(1 \mathrm{mg} \mathrm{ml}^{-1}\right.$; Sigma-Aldrich) in Dulbecco's modified Eagle's medium containing $10 \%$ fetal bovine serum (Hyclone). After 2 days of differentiation ('day 2'), the medium was replaced with Dulbecco's modified Eagle's medium containing only 10\% fetal bovine serum and insulin $\left(1 \mathrm{mg} \mathrm{ml}^{-1}\right)$, and it was again replaced at day 4. On day 6, the medium was replaced with Dulbecco's modified Eagle's medium containing 10\% fetal bovine serum. 3T3L1 adipocytes, and 8 days after differentiation, they were treated with $10 \mathrm{ng} \mathrm{ml}^{-1}$ recombinant BAFF (R\&D Systems, Minneapolis, MN, USA) for $2,4,8$ or $12 \mathrm{~h}$. As a control, cells were cultured in the same condition but without BAFF treatment. Cells and media were collected for RNA extraction and enzyme-linked immunosorbent assay (ELISA), respectively.

\section{Macrophage and adipocyte coculture system}

In the direct coculture system, RAW 264.7 macrophages were added to fully differentiated 3T3-L1 adipocytes in six-well dishes at concentrations of $1 \times 10^{5}$ cells per well. ${ }^{29}$ As controls, the same concentration of RAW 264.7 macrophages and 3T3-L1 adipocytes were separately cultured in six-well plates for $24 \mathrm{~h}$, and then harvested together. Indirect coculture was performed by using the Transwell system (Corning, Acton, MA, USA) with $0.4-\mu \mathrm{m}$ porous membranes to separate the upper and lower chambers. Differentiated 3T3-L1 cells were cultured and differentiated in the lower chamber, whereas $1 \times 10^{5}$ RAW 264.7 cells were cultured in the upper chamber. As controls, macrophages and 3T3-L1 adipocytes were separately cultured in six-well plates for $24 \mathrm{~h}$ and each cell type was harvested.

\section{Diet-induced obese mice}

Six-week-old C57BL/6 mice were purchased from Central Lab. Animal (Seoul, Korea). Mice were fed a standard chow diet for a week to be stabilized. The mice were separated into two groups: chow diet group and high-fat diet group. Mice in the chow diet group were fed a standard chow diet, and mice in the high-fat diet group were fed a $40 \%$ fat diet for 24 weeks. All mice were housed in cages on a 12-h light/dark cycle, at a temperature of $22 \pm 1{ }^{\circ} \mathrm{C}$ and humidity of $55 \pm 5 \%$.

\section{RNA extraction and complementary DNA synthesis}

Total RNA was isolated from 3T3-L1 adipocytes using QIAzol reagent (QIAgen, Hilden, Germany). Complementary DNA synthesis was performed with $1 \mu \mathrm{g}$ of total RNA using ImProme-II reverse transcriptase (Promega, Madison, WI, USA). Reactions were incubated at one cycle of $24^{\circ} \mathrm{C}$ for $5 \mathrm{~min}, 42^{\circ} \mathrm{C}$ for $60 \mathrm{~min}$ and $70{ }^{\circ} \mathrm{C}$ for 15 min. Synthesized complementary DNA was diluted with $80 \mu \mathrm{l}$ of double-distilled water.

\section{Real-time PCR}

Real-time reverse transcription (RT)-PCR analysis was performed using an Applied Biosystems 7500 Real-Time PCR system (Applied Biosystems, Foster City, CA, USA). The complementary DNA, appropriate primers, ROX dye and HotStart-IT SYBR Green qPCR Master Mix (USB, Cleveland, OH, USA) were incubated in the Applied Biosystems 7500 Real-Time PCR system for an initial denaturation at $94^{\circ} \mathrm{C}$ for $2 \mathrm{~min}$, followed by 45 cycles at $95^{\circ} \mathrm{C}$ for $15 \mathrm{~s}$ and $60^{\circ} \mathrm{C}$ for $1 \mathrm{~min}$. Oligonucleotide primers are listed in Table 1.

\section{Western blot}

After the experimental treatment, cells were washed three times with ice-cold phosphate-buffered saline and lysed with PRO-PREP Protein Extraction Solution (iNtRON Biotechnology, Seoul, Korea). The cell lysates were incubated at $4{ }^{\circ} \mathrm{C}$ with rotation for $30 \mathrm{~min}$. Insoluble materials and lipids were removed by centrifugation at 13000 r.p.m. for $5 \mathrm{~min}$ at $4{ }^{\circ} \mathrm{C}$. The total concentration of extracted proteins was measured using a Bradford assay. The proteins were separated by $10 \%$ SDS-polyacrylamide gel electrophoresis and transferred onto nitrocellulose membranes. After the membranes were blocked with Tris-buffered saline and Tween-20 (10 mM Tris, $150 \mathrm{~mm} \mathrm{NaCl}, 0.01 \%$ Tween-20, pH 7.6) containing 5\% nonfat milk for $1 \mathrm{~h}$ at room temperature, the membranes were incubated with the appropriate primary antibodies. To detect the antigen-bound antibodies, the blots were treated with secondary antibodies conjugated to horseradish peroxidase. Immunoreactivity was detected by using an enhanced chemiluminescence western blotting detection system.

\section{ELISA}

The mouse BAFF/B-lymphocyte stimulator ELISA kit was purchased from R\&D Systems. The mouse Leptin capture antibody and 
Table 1 Gene-specific primers used for RT-PCR

\begin{tabular}{|c|c|c|c|}
\hline Gene name & Accession no. & & Sequence \\
\hline \multirow[t]{2}{*}{$B A F F$} & NM_033622 & Forward & 5'-TGCTACTCGGCTGGCATCGC-3' \\
\hline & & Reverse & 5'-GCGCGGGCTCCGTTTCTCAT-3' \\
\hline$\beta$-Actin & & Reverse & 5'-TCCCTCTCAGCTGTGGTGGTGAA-3' \\
\hline Leptin & NM_008493 & Forward & 5'-GAGACCCCTGTGTCGGTTC-3' \\
\hline Adiponectin & & Reverse & 5'-CCCTGGCTTTATGCTCTTTGC-3' \\
\hline \multirow[t]{2}{*}{$M C P-1$} & NM_011331.2 & Forward & 5'-TTAAAAACCTGGATCGGAACCAA-3' \\
\hline & & Reverse & 5'-GCATTAGCTTCAGATTTACGGGT-3' \\
\hline \multirow[t]{2}{*}{$\operatorname{cox}-2$} & NM_011198 & Forward & 5'-TGAGCAACTATTCCAAACCAGC-3' \\
\hline & & Reverse & 5'-GCACGTAGTCTTCGATCACTATC-3' \\
\hline \multirow[t]{2}{*}{$B A F F-R$} & NM_028075.2 & Forward & 5'-GACCCTGGTGGGTCTAGTGA-3' \\
\hline & & Reverse & 5'-GTAGGAGCTGAGGCATGAGG-3' \\
\hline \multirow[t]{2}{*}{$B C M A$} & NM_011608.1 & Forward & 5'-ATCTTCTTGGGGCTGACCTT-3' \\
\hline & & Reverse & 5'-CTCACAGGTGCACTCTTCCA-3' \\
\hline \multirow[t]{2}{*}{ TACI } & NM_021349.1 & Forward & 5'-CTACTGCACACTGGGGGTCT-3' \\
\hline & & Reverse & 5'-CTCCTGAGTGGGAGAACTGC-3' \\
\hline
\end{tabular}

Real-time reverse transcription (RT)-PCR experiments used the above primers.

biotinylated antibody were also purchased from R\&D Systems. All experiments were performed according to the manufacturer's instructions.

\section{Statistical analysis}

The data were analyzed by Student's $t$-test; $P<0.05$ was considered significant.

\section{RESULTS}

\section{Leptin and adiponectin expression decreases} in BAFF-treated adipocytes

Previously, we showed that BAFF and its receptors are expressed by 3 T3-L1 adipocytes. ${ }^{28}$ To determine whether adipokine expression is regulated by treatment with BAFF, we examined the expression of leptin and adiponectin in BAFF-treated 3T3$\mathrm{L} 1$ adipocytes. The mRNA expression of leptin and adiponectin was estimated by real-time RT-PCR. The mRNA expression level of those genes decreased 0.4-fold in $2 \mathrm{~h}$ compared with the control group, and the decreased expression was maintained for up to $12 \mathrm{~h}$ (Figures 1a and b). Protein expression of leptin and adiponectin in culture medium was estimated by ELISA and western blot analysis, respectively. In agreement with the realtime RT-PCR data, protein expression of these genes also decreased (Figures $1 \mathrm{a}$ and $\mathrm{b}$ ).

mRNA expression of proinflammatory adipokines significantly increases in BAFF-treated 3T3-L1 adipocytes To determine whether the expression of inflammatory adipokines is modulated by BAFF, we examined the expression of the proinflammatory adipokines MCP-1, IL-6, COX-2 and haptoglobin in BAFF-treated 3T3-L1 adipocytes at different time periods. The mRNA expression of MCP-1, IL-6, COX-2 and haptoglobin were estimated by real-time RT-PCR. The mRNA expression of those genes increased the most $2 \mathrm{~h}$ after treatment with BAFF, and returned to the basal level of expression at $12 \mathrm{~h}$. MCP-1 expression increased 4.2-fold (Figure 2a), IL-6 increased 1.6-fold (Figure 2b), COX-2 increased 6-fold (Figure 2c) and haptoglobin increased up to 2-fold (Figure 2d), as compared with the control group.

BAFF expression increases by coculture of 3T3-L1 and RAW 264.7 cells

BAFF is expressed in myeloid cell lines, and in our previous results, we showed that BAFF could regulate adipokine expression (Figures 1 and 2). Thus, we hypothesized that BAFF could have a role in regulating adipocyte and macrophage interaction in adipose tissue. To test this, mature 3T3-L1 adipocytes and RAW 264.7 macrophages were cultured together for $24 \mathrm{~h}$, both directly and indirectly. There was cell-to-cell interaction in the direct coculture, but not in the indirect coculture system, because the two cell types were separated by a $0.4-\mu \mathrm{m}$ pore insert. The expression of BAFF was estimated by real-time RT-PCR, western blot analysis and ELISA. The mRNA expression of BAFF increased by both direct coculture (Figure $3 \mathrm{a}$ ) and indirect coculture (Figure $3 \mathrm{~d}$ ) of 3T3-L1 adipocytes and RAW 264.7 macrophages. Direct coculturing of cells resulted in increased BAFF protein 

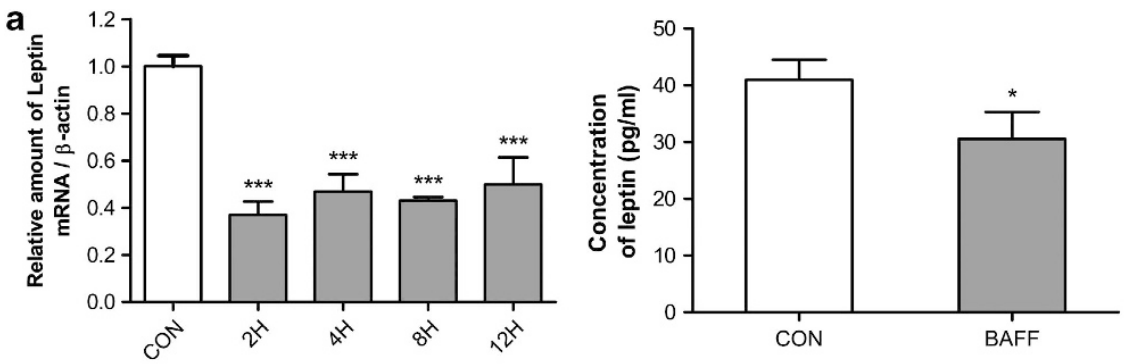

b
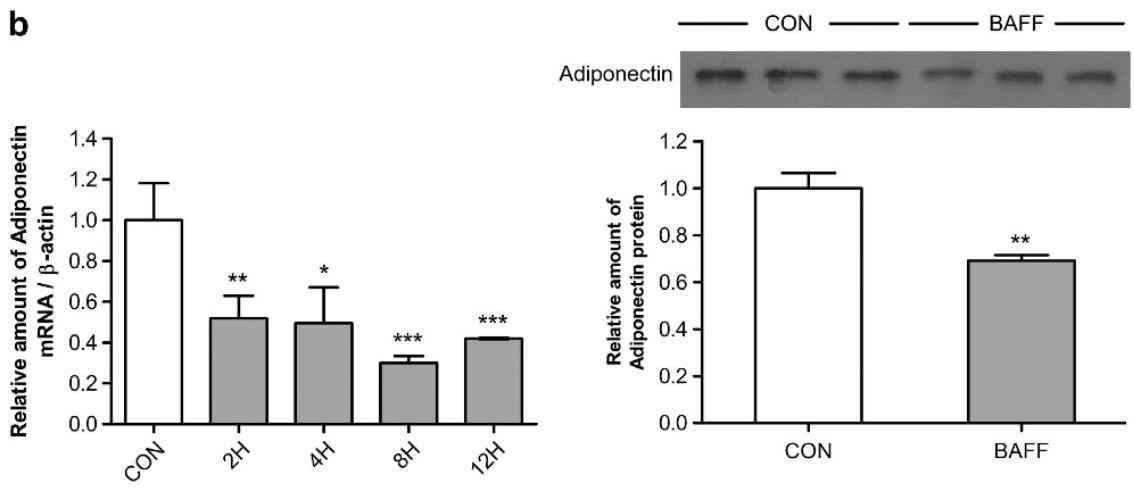

Figure 1 Expression of leptin and adiponectin in BAFF-treated 3T3-L1 adipocytes. At day 8 after inducing differentiation, adipocytes were cultured in a 35-mm dish with $10 \mathrm{ng} \mathrm{ml}^{-1}$ BAFF for 2, 4, 8 or $12 \mathrm{~h}$. As control (CON), cells were cultured in the same condition but without BAFF treatment. Graphs represent mRNA and protein expression of (a) leptin and (b) adiponectin. mRNA analysis was expressed relative to untreated control cells and represent means \pm s.e. Experiments were conducted twice, each with triplicate samples. Means with letters are significantly different $\left({ }^{*} P<0.05,{ }^{* *} P<0.01\right.$ and $\left.{ }^{* * *} P<0.001\right)$ by Student's $t$-test.
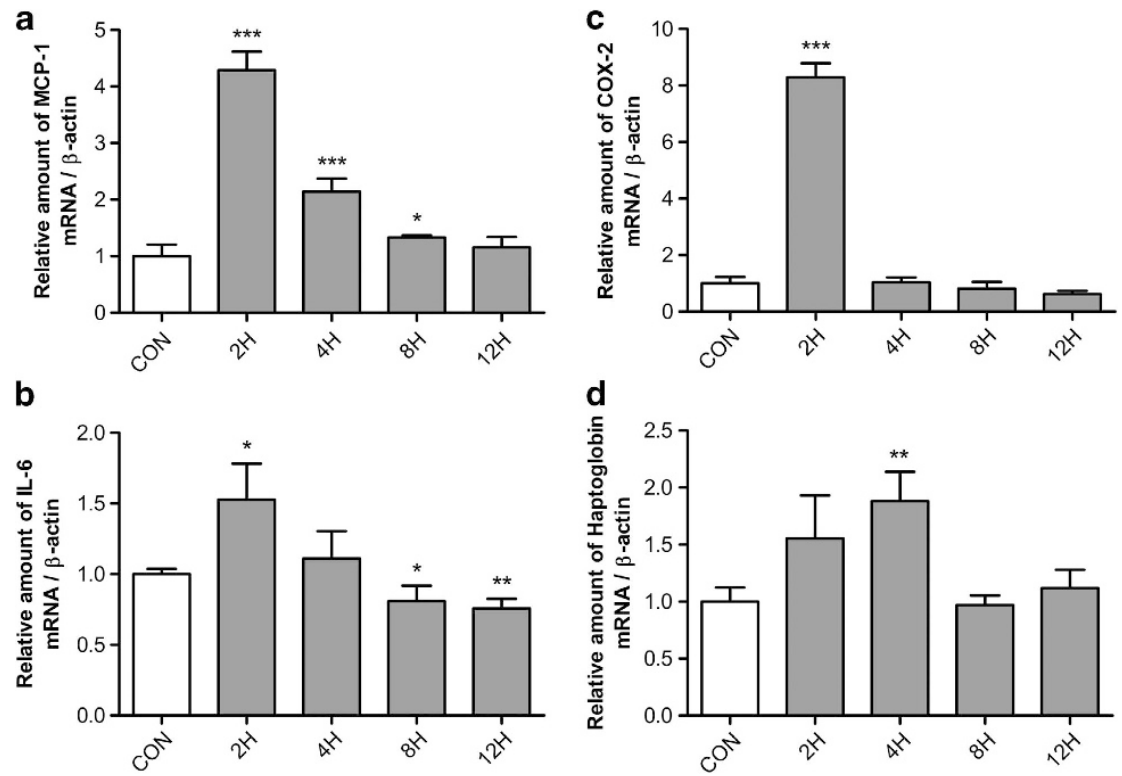

Figure 2 mRNA expression of IL-6, COX-2, MCP-1 and haptoglobin in BAFF-treated 3T3-L1 adipocytes. At day 8 after inducing differentiation, adipocytes were cultured in a $35-\mathrm{mm}$ dish with $10 \mathrm{ngml}-1$ BAFF for $2,4,8$ or $12 \mathrm{~h}$. As control (CON), cells were cultured in the same condition but without BAFF treatment. The graph represents mRNA expression of (a) IL-6, (b) COX-2, (c) MCP-1 and (d) haptoglobin. mRNA analysis was expressed relative to untreated control cells and represent means \pm s.e. Experiments were conducted twice, each with triplicate samples. Means with letters are significantly different $\left({ }^{*} P<0.05,{ }^{* *} P<0.01\right.$ and $\left.{ }^{* * *} P<0.001\right)$ by Student's $t$-test.

expression (Figure 3e), and BAFF secretion into the medium was also increased by both direct and indirect coculture (Figure 3b). Interestingly, increased BAFF expression in RAW
264.7 cells by 3T3-L1 cells was higher than that in 3T3-L1 cells by RAW 264.7 cells (Figure 3d). BAFF-R expression was also modulated by coculture of 3T3-L1 adipocytes and RAW 264.7 
a

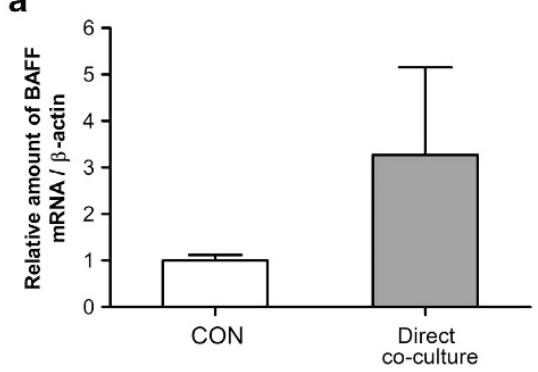

b
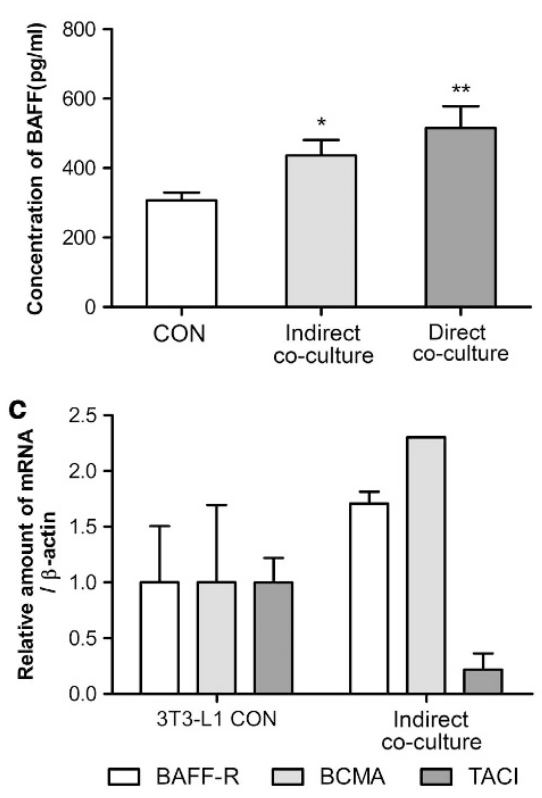

d

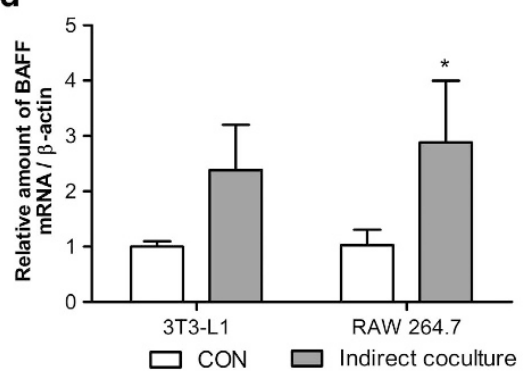

e
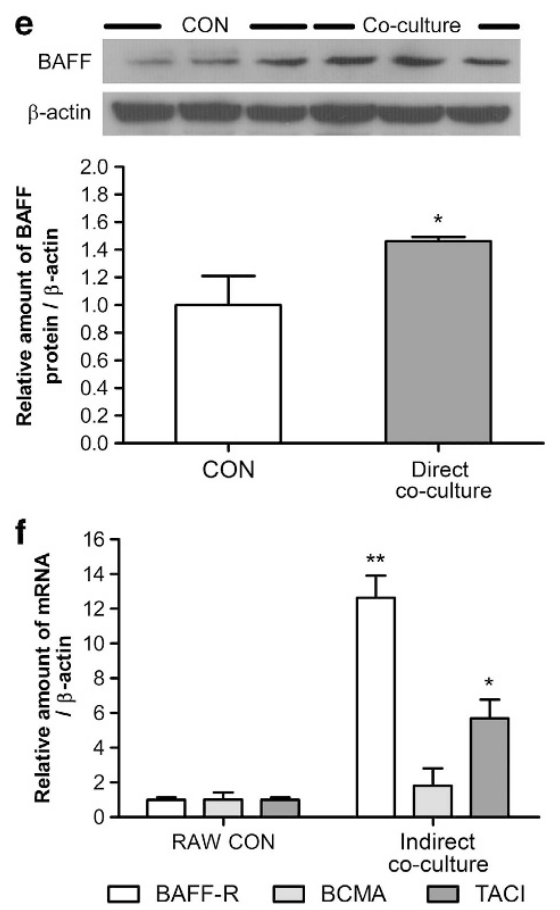

Figure 3 BAFF expression in the 3T3-L1 adipocyte and RAW 264.7 macrophage coculture system. At day 8 after inducing differentiation, adipocytes were cultured in six-well plates with RAW 264.7 macrophages for $24 \mathrm{~h}$. Control (CON) group was cultured in the same condition but without RAW 264.7 macrophages. In the direct coculture system, two types of cell were separately cultured for $24 \mathrm{~h}$, and then collected together. Graphs represent (a) mRNA expression of BAFF in direct coculture, (b) secreted BAFF, (c) mRNA expression of BAFF receptors in indirect cocultured 3T3-L1 adipocytes, (d) mRNA expression of BAFF in indirect coculture, (e) BAFF in cell lysates and (f) mRNA expression of BAFF receptors in indirect cocultured RAW 264.7 macrophages. Data were expressed relative to control groups and represent means \pm s.e. Experiments were conducted twice, each with triplicate samples. Means with letters are significantly different $\left({ }^{*} P<0.05\right.$ and $\left.{ }^{* *} P<0.01\right)$ by Student's $t$-test.

macrophages. In 3T3-L1 cells, the mRNA expression of BAFF-R and BCMA increased but that of TACI decreased (Figure 3c), and in RAW 264.7 macrophages the mRNA expression of BAFF-R and TACI increased but that of BCMA remained the same (Figure 3f).

\section{Increased expression of inflammatory molecules in RAW 264.7 macrophages following BAFF treatment}

In the previous results, we showed that not only did BAFF expression in RAW 264.7 increase on coculturing with 3T3-L1 adipocytes (Figures 3a,b,d and e), but that BAFF-R expression in RAW 264.7 macrophages was also changed by coculture with 3T3-L1 adipocytes (Figures $3 \mathrm{c}$ and $\mathrm{f}$ ). From this, we hypothesized that increased BAFF in 3T3-L1 cells may have an inflammatory effect on RAW 264.7 macrophages. Therefore, RAW 264.7 macrophages were treated with 10 and $100 \mathrm{ng} \mathrm{ml}^{-1}$ of BAFF for $2 \mathrm{~h}$. BAFF- $\mathrm{R}$ expression was modulated by BAFF (Figure 4a). We also examined the change in expression of inflammatory molecules such as nitric oxide synthase and IL-6. The mRNA expression of nitric oxide synthase (Figure 4b) and IL-6 (Figure 4c) and protein expression of nitric oxide synthase increased (Figure 4d) following BAFF treatment.

Increased BAFF expression in adipose tissue of DIO mice In a previous study, BAFF expression was altered in WAT of $o b / o b$ mice. ${ }^{28}$ In this study, we wanted to determine whether BAFF expression is also regulated in DIO mice. We examined 

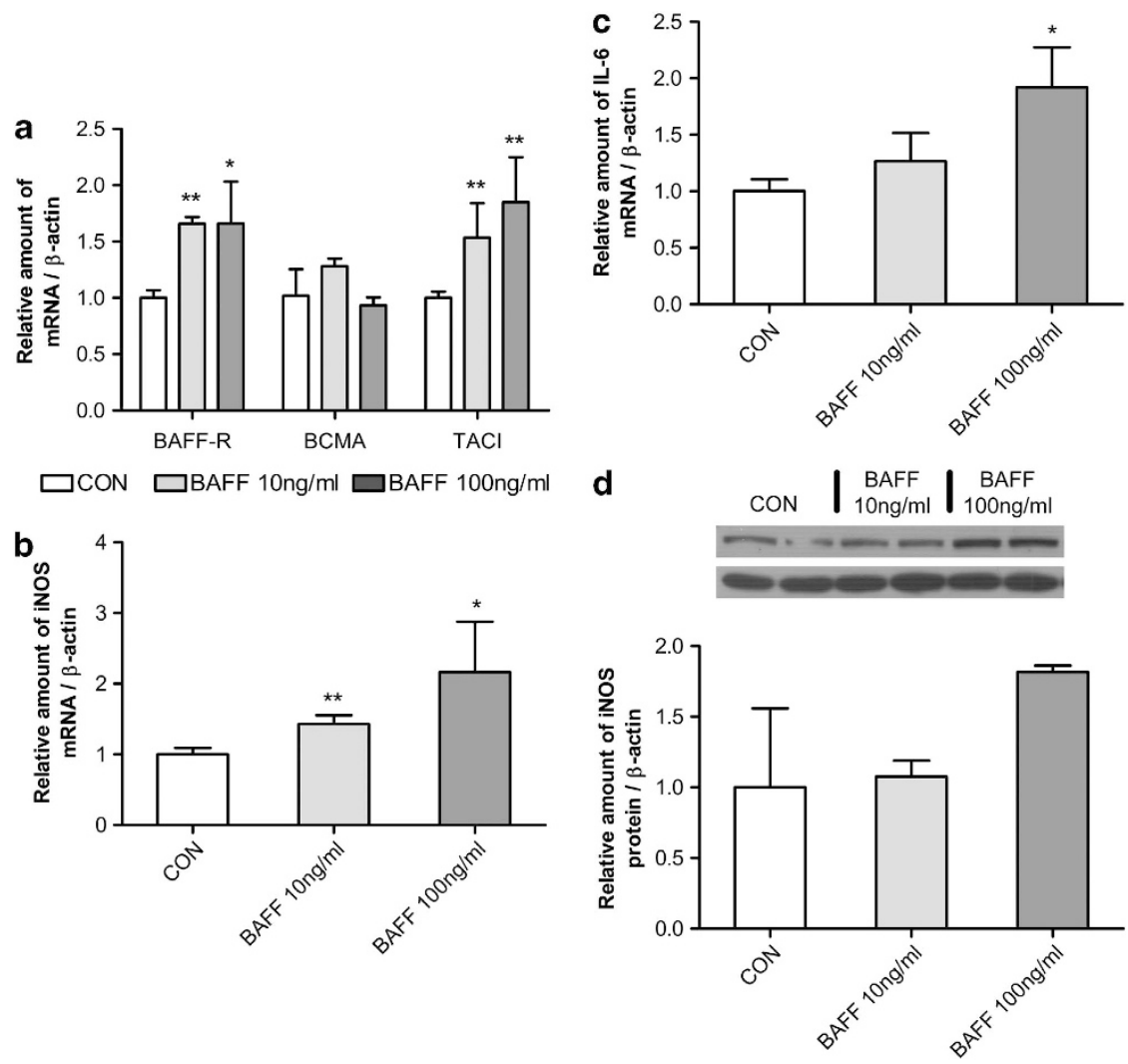

Figure 4 Regulation of BAFF receptor and inflammatory molecule expression in RAW 264.7 macrophages by BAFF treatment. One day after cell subculture, RAW 264.7 macrophages were cultured in a 35-mm dish with 10 or $100 \mathrm{ng} \mathrm{ml}^{-1}$ BAFF for $2 \mathrm{~h}$. As control (CON), cells were cultured in the same condition but without BAFF treatment. The graph represents mRNA expression of (a) BAFF receptors, (b) nitric oxide synthase (iNOS), (c) IL-6 and (d) protein expression of iNOS. mRNA analysis was expressed relative to untreated control cells and represent means \pm s.e. Experiments were conducted twice, each with triplicate samples. Means with letters are significantly different $\left({ }^{*} P<0.05\right.$ and $\left.{ }^{* *} P<0.01\right)$ by Student's $t$-test.

BAFF expression in the epididymal adipose tissue (Figures $5 \mathrm{a}$ and $\mathrm{b}$ ), and the subcutaneous adipose tissue (Figures $5 \mathrm{c}$ and $\mathrm{d}$ ) of DIO mice by real-time RT-PCR and western blot analysis. The mRNA and protein expression of BAFF in epididymal adipose tissue increased up to 2 - and 3-fold, respectively. In addition, the mRNA expression and protein expression of BAFF in subcutaneous adipose tissue increased up to 6- and 1.8 -fold, respectively.

\section{DISCUSSION}

In this study, we investigated the function of BAFF in 3T3-L1 adipocytes and in RAW 264.7 macrophages, and the regulation of BAFF expression in the coculture of adipocytes and macrophages, as well as in the fat pads of DIO mice.

Our results show that the expression of leptin and adiponectin decreases in BAFF-treated 3T3-L1 adipocytes. BAFF has three different receptors, which are also expressed on 3T3L1 adipocytes. ${ }^{28}$ The three receptors seem to have different functions in adipocytes, and it is thought that leptin and adiponectin may be regulated by different receptors. Adiponectin and leptin are closely associated with metabolic diseases caused by obesity, ${ }^{30,31}$ and thus BAFF might also affect the development of metabolic diseases through the regulation of these adipokines.

The expression of proinflammatory adipokines, such as IL-6, MCP-1, COX-2 and haptoglobin, is highly increased in BAFF-treated 3T3-L1 adipocytes. Increased MCP-1 could recruit more macrophages to adipose tissue, and increased IL-6, COX-2 and haptoglobin could promote inflammation. Infiltrated macrophages might produce more BAFF, and BAFF could further increase the expression of those proinflammatory adipokines. From these data, we propose that BAFF could be a regulator of adipokines and a possible inducer of inflammation in adipocytes.

We examined the modulation of BAFF expression in coculture of 3T3-L1 adipocytes and RAW 264.7 macrophages. In both the indirect and direct coculture systems, BAFF mRNA and protein expression increased. The expression of BAFF-Rs in RAW 264.7 macrophages and 3T3-L1 adipocytes is also modulated by coculture of 3T3-L1 adipocytes and RAW 264.7 macrophages. Interestingly, the increased level of BAFF expression in RAW 264.7 cells by 3T3-L1 cells was higher than that in the 3T3-L1 cells by RAW 264.7 coculture, and these two cell types show different expression levels of BAFF-Rs. We expect that BAFF itself could affect those cells, and that certain 

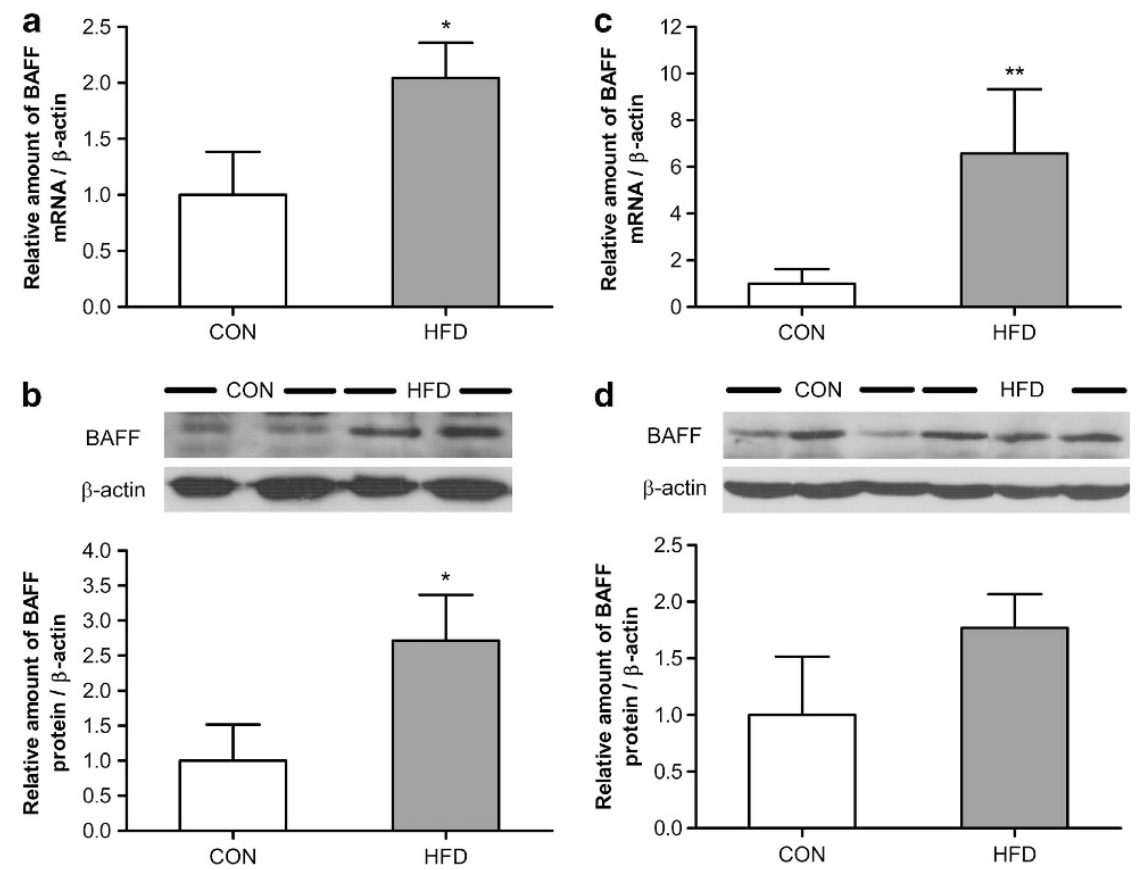

Figure 5 Regulation of BAFF expression in adipose tissue by diet-induced obesity. Mice (6 weeks old) were divided into two groups after stabilization. One group was fed a standard chow diet, and the other was fed a $40 \%$ fat diet for 24 weeks. mRNA was isolated from the adipose tissue of each (EAT, SAT). Graphs represent (a) mRNA expression of BAFF in EAT, (b) protein expression of BAFF in EAT, (c) mRNA expression of BAFF in SAT and (d) protein expression of BAFF in SAT. Data were expressed relative to control groups and represent means \pm s.e. Means with letters are significantly different $\left({ }^{*} P<0.05\right.$ and $\left.{ }^{* *} P<0.01\right)$ by Student's $t$-test.

molecules from 3T3-L1 adipocytes may induce BAFF expression in RAW 264.7 macrophages. Further study might be needed to identify the molecules that increase BAFF expression.

BAFF-R expression in RAW 264.7 macrophages is also changed by coculture with 3T3-L1 adipocytes, and thus we assume that increased BAFF in 3T3-L1 cells may have certain effects on RAW 264.7 macrophages. We also show that BAFF can induce the expression of proinflammatory molecules such as nitric oxide synthase and IL-6 in RAW 264.7 macrophages. From these data, we propose that increased BAFF by coculture of 3T3-L1 adipocytes and RAW 264.7 macrophages might affect RAW 264.7 macrophages and synergistically promote inflammation.

BAFF expression also increased in the fat pad of DIO mice. In WAT of DIO mice, BAFF mRNA and protein expression increased. In a previous study, we showed that BAFF expression also increased in WAT of $o b / o b$ mice. ${ }^{28}$ It has already been reported that more macrophages infiltrate into WAT of obese mice than that of normal mice. ${ }^{32}$ These data indicate that BAFF increases the expression of MCP-1, and because of that more macrophages infiltrate into adipose tissue. Therefore, we can safely attribute enhanced BAFF expression to more macrophages infiltrating into adipose tissues.

Taken together, we propose that BAFF is a possible regulator of adipokines and a possible mediator of adipocyte and macrophage interaction in adipose tissue.

\section{ACKNOWLEDGEMENTS}

This research was supported by the National Research Foundation of Korea (KRF-2010-0009677).

1 Fantuzzi G. Adipose tissue, adipokines, and inflammation. J Allergy Clin Immunol 2005; 115: 911-919.

2 Arner P. Insulin resistance in type 2 diabetes - role of the adipokines. Curr Mol Med 2005; 5: 333-339.

3 Lau DC, Dhillon B, Yan H, Szmitko PE, Verma S. Adipokines: molecular links between obesity and atherosclerosis. Am J Physiol Heart Circ Physiol 2005; 288: H2O31-H2O41.

4 Beuther DA, Weiss ST, Sutherland ER. Obesity and asthma. Am J Respir Crit Care Med 2006; 174: 112-119.

5 Mackay F, Woodcock SA, Lawton P, Ambrose C, Baetscher M, Schneider P et al. Mice transgenic for BAFF develop lymphocytic disorders along with autoimmune manifestations. J Exp Med 1999; 190: 1697-1710.

6 Woo YJ, Yoon BY, Jhun JY, Oh HJ, Min SW, Cho ML et al. Regulation of B cell activating factor(BAFF) receptor expression by $\mathrm{NF}-\mathrm{KB}$ signaling in rheumatoid arthritis B cells. Exp Mol Med 2011; 43: 350-357.

7 Craxton A, Magaletti D, Ryan EJ, Clark EA. Macrophage- and dendritic celldependent regulation of human $\mathrm{B}$-cell proliferation requires the TNF family ligand BAFF. Blood 2003; 101: 4464-4471.

8 Schneider P, Mackay F, Steiner V, Hofmann K, Bodmer JL, Holler N et al. BAFF, a novel ligand of the tumor necrosis factor family, stimulates $B$ cell growth. J Exp Med 1999; 189: 1747-1756.

9 Moore PA, Belvedere O, Orr A, Pieri K, LaFleur DW, Feng P et al. BLyS: member of the tumor necrosis factor family and $B$ lymphocyte stimulator. Science 1999; 285: 260-263.

10 Mackay F, Pascal S. Cracking the BAFF code. Nat Rev Immunol 2009; 9 : 491-502.

11 Ng LG, Sutherland AP, Newton R, Qian F, Cachero TG, Scott ML et al. $B$ cell-activation factor belonging to the TNF family (BAFF)- $R$ is the 
principal BAFF receptor facilitating BAFF costimulation of circulating $T$ and B cells. J Immunol 2004; 173: 807-817.

12 Huard B, Schneider P, Mauri D, Tschopp J, French LE. T cell costimulation by the TNF ligand BAFF. J Immunol 2001; 167: 6225-6231.

13 von Bulow GU, Bram RJ. NF-AT activation induced by a CAML interacting member of the tumor necrosis factor receptor superfamily. Science 1997; 278: 138-141.

14 Thompson JS, Bixler SA, Qian F, Vora K, Scott ML, Cachero TG et al. BAFF-R, a newly identified TNF receptor that specifically interacts with BAFF. Science 2001; 293: 2108-2111.

15 Mackay F, Ambrose C. The TNF family members BAFF and APRIL: the growing complexity. Cytokine Growth Factor Rev 2003; 14: 311-324.

16 Brennan AM, Mantzoros CS. Drug insight: the role of leptin in human physiology and pathophysiology emerging clinical applications. Nat Clin Pract Endocrinol Metab 2006; 2: 318-327.

17 Wellen KE, Hotamisligil GS. Obesity-induced inflammatory changes in adipose tissue. J Clin Invest 2003; 112: 1785-1788.

18 Diez JJ, Iglesias P. The role of the novel adipocyte-derived hormone adiponectin in human disease. Eur J Endocrinol 2003; 148: 293-300.

19 Xia M, Sui Z. Recent developments in CCR2 antagonists. Expert Opin Ther Patents 2009; 19: 295-303.

20 Gabay C. Interleukin-6 and chronic inflammation. Arthritis Res Ther 2006; 8(Suppl 2): S3.

21 Trayhurn P, Wood IS. Adipokines: inflammation and the pleiotropic role of white adipose tissue. Br J Nutr 2004; 92: 347-355.

22 Christopher SW, Moss M, Raymond ND. The role of cyclooxygenases in inflammation, cancer, and development. Oncogene 1999; 18: 7908-7916.

23 Quaye IK. Haptoglobin, inflammation, and disease. Trans $R$ Soc Trop Med Hyg 2008; 102: 735-742.

24 Do MS, Jeong HS, Choi BH, Hunter L, Langley S, Pazmany L et al. Inflammatory gene expression patterns revealed by DNA microarray analysis in TNF-alpha-treated SGBS human adipocytes. Yonsei Med $J$ 2006; 47: 729-736.
25 Pelekanou V, Kampa M, Kafousi M, Darivianaki K, Sanidas E, Tsiftsis DD et al. Expression of TNF-superfamily members BAFF and APRIL in breast cancer: Immunohistochemical study in 52 invasive ductal breast carcinomas. BMC Cancer 2008; 20: 76.

26 Alexaki VI, Notas G, Pelekanou V, Kampa M, Valkanou M, Theodoropoulos $\mathrm{P}$ et al. Adipocytes as immune cells: differential expression of TWEAK, BAFF, and APRIL and their receptors (Fn14, BAFF-R, $\mathrm{TACl}$, and $\mathrm{BCMA}$ ) at different stages of normal and pathological adipose tissue development. J Immunol 2009; 183: 5948-5956.

27 Hamada M, Abe M, Miyake T, Kawasaki K, Tada F, Furukawa S et al. B cellactivating factor controls the production of adipokines and induces insulin resistance. Obesity 2011; 19: 1915-1922.

$28 \mathrm{Kim} \mathrm{YH}$, Choi BH, Cheon HG, Do MS. B cell activation factor (BAFF) is a novel adipokine that links obesity and inflammation. Exp Mol Med 2009; 41: 208-216.

29 Takayoshi S, Junko N, Yoshihiro OA. Paracrine loop between adipocytes and macrophages aggravates inflammatory changes: role of free fatty acids and tumor necrosis factor $\alpha$. Arterioscler Thromb Vasc Biol 2005; 25: 2062-2068.

30 Whitehead JP, Richards AA, Hickman IJ, Macdonald GA, Prins JB Adiponectin - a key adipokine in the metabolic syndrome. Diabetes Obes Metab 2006; 8: 264-280.

31 Patel SB, Reams GP, Spear RM, Freeman RH, Villarreal D. Leptin: linking obesity, the metabolic syndrome, and cardiovascular disease. Curr Hypertens Rep 2008; 10: 131-137.

32 Takahashi K, Mizuarai S, Araki H, Mashiko S, Ishihara A, Kanatani A et al. Adiposity elevates plasma MCP-1 levels leading to the increased CD11bpositive monocytes in mice. J Biol Chem 2003; 278: 46654-46660.

(c) (i) () $\odot$ This work is licensed under a Creative Commons Attribution-NonCommercial-NoDerivs 3.0 Unported License. To view a copy of this license, visit http:// creativecommons.org/licenses/by-nc-nd/3.0/ 